\title{
Relación entre carcinoma hepatocelular, síndrome metabólico y la enfermedad grasa no alcohólica del hígado
}

Relationship between hepatocellular carcinoma, metabolic syndrome and non-alcoholic fatty liver disease

\section{Sr. Editor:}

En 1985 en la revista Acta Medica Scandinavica apareció un editorial en la que se señalaba la asociación entre obesidad y riesgo de enfermedad cardiovascular (1), desde entonces, se han realizado estudios para identificar los posibles factores o causas y la relación del sobrepeso, obesidad (principalmente con incremento del perímetro abdominal) (2).

En mayo de este año apareció el artículo "La relación entre carcinoma hepatocelular, síndrome metabólico y la enfermedad grasa del hígado no alcohólica: ¿Cuáles argumentos clínicos?” (3) que merece tener toda nuestra atención ya que, en la actualidad, estamos observando el incremento del sobrepeso, obesidad con el incremento del perímetro abdominal, en una identidad denominada síndrome metabólico, en rangos epidémicos y con asociación a virus y con riesgo incrementado para varios tipos de cáncer. El mismo autor señala que a nivel hepático, la resistencia a insulina y la esteatosis hepática producen cambios inflamatorios y angiogénicos que se asocian con el incremento de carcinoma hepático (3).

Años antes, Pagano et al (4) indicaban que el deterioro de la regulación de la insulina, se asociaba a menudo con el síndrome metabólico y podían jugar un rol causal en la patogénesis de la enfermedad grasa del hígado no alcohólica (4).

La intención de esta misiva es que los investigadores tengan en cuenta esta información al realizar estudios, sobre todo en la cadena de sobrepeso, obesidad (con perímetro abdominal incrementado), síndrome metabólico, el desarrollo de hígado graso y el riesgo de carcinoma hepatocelular $\mathrm{y}$, además, no deben olvidar a la hepatitis A, a la cual se le menciona como la más benigna; sin embargo, en mi práctica clínica, en una gran cantidad de pacientes con sobrepeso u obesidad, con síndrome metabólico e hígado graso que han tenido hepatitis viral $\mathrm{A}$ anictérica en algún momento de su vida, con serología para hepatitis B y $\mathrm{C}$ no reactivas, por lo que debemos señalar, ante las evidencias que están apareciendo, la importancia de la vacuna contra la hepatitis A desde niño.

Jesús L. Chirinos MDF, Dr.PH ${ }^{1}$

\section{REFERENCIAS BIBLIOGRÁFICAS}

1. Björntorp P. Obesity and risk of cardiovascular disease. Acta Medica Scandinavica. 1985; 218: 145147.

2. Björntorp P. The Associations between obesity, adipose tissue distribution and disease. Acta Medica Scandinavica. 1987; 222: 121-134.

3. Rosmorduc O. Relationship between hepatocellular carcinoma, metabolic syndrome and non-alcoholic fatty liver disease: Which clinical arguments? Annales d'Endocrinologie. 2013; 74(2):115-120.

4. Pagano G, Pacini G, Musso G, et al. Nonalcoholic steatohepatitis, insulin resistance, and metabolic syndrome: Further evidence for an etiologic association. Hepatology. 2002; 35: 367-372.

Recibido: 06/08/2013

Profesor Principal Facultad de Salud Pública, Universidad Peruana Cayetano Heredia. Lima, Perú. 